\title{
Rapid deterioration of visual fields during bromocriptine-induced pregnancy in a patient with a pituitary adenoma
}

\author{
J. T. W. VAN DALEN AND E. L. GREVE \\ From the Department of Ophthalmology, University of Amsterdam (Wilhelmina Gasthuis)
}

SUMMARY A 28-year-old woman with an amenorrhoea-galactorrhoea syndrome was suspected of a microadenoma of the pituitary. She was treated with bromocriptine. In the subsequent pregnancy she developed rapid deterioration of the visual fields (ODS). A large temporal defect in the right eye and a moderate temporal defect in the left eye appeared in the 28th week of pregnancy, threatening the visual acuity of both eyes. Other examinations showed no evident lesion of the sellar region. An adenoma of the pituitary was removed, and the visual fields returned to normal after operation.

Secondary amenorrhoea in combination with galactorrhoea is highly suggestive of the presence of a pituitary or parapituitary lesion. When ovulation is induced by chemical means in such cases, careful attention should be paid to changes in these pituitary or parapituitary lesions.

Patients with amenorrhoea and galactorrhoea were described by Corbey et al. (in press), Lamberts et al. (in press), and Kajtar and Tomkin (1971). In subsequent (induced) pregnancies visual field defects developed, leading to termination of the pregnancy in the 39th week in one case (Corbey), spontaneous regression of the defects after the 36th week of pregnancy (Lamberts), and performance of hypophysectomy in a third patient (Kajtar and Tomkin). In this third case there was gross erosion of the posterior clinoids, and a pituitary adenoma was found.

\section{Case history}

A woman, now aged 25 years, was first seen in our ophthalmology department in July 1975, having been referred to us by the gynaecologist. After a period on oral contraceptives (1970-2) she had developed oligomenorrhoea and galactorrhoea, followed in 1973 by amenorrhoea. In July 1975 high prolactin levels were found $(87 \mathrm{ng} / \mathrm{ml}$; normal value $20 \mathrm{ng} / \mathrm{ml}$ ), and it was concluded that this patient had a pro-

Address for reprints: Dr J. Th. W. van Dalen, Department of Ophthalmology, University of Amsterdam (Wilhelmina Gasthuis), le Helmersstraat 104 Amsterdam, The Netherlands lactin-producing microadenoma of the pituitary gland. Physical examination showed no special features. Tomography of the sellar region showed a slight and equivocal irregularity of the floor of the sella turcica. In March 1976 bromocriptine treatment was started to restore ovarian function. The subsequent pregnancy was normal from the obstetric point of view, and the patient had no complaints. The prolactin level returned to normal $(18 \mathrm{ng} / \mathrm{ml})$, and a stereo $x$-ray of the sella turcica showed no abnormalities. In the meantime periodic assessments of the visual fields were started.

On 4 August 1976 the first bitemporal defects were found (Fig. 1). On 27 August 1976 a dense temporal defect had developed in the right eye, including a relative central defect. The left eye showed an increase of the temporal defect (Fig. 2). Visual acuity was OD $5 / 5$, OS $5 / 5$. In Fig. 3 the follow-up by means of static perimetry is demonstrated. As a routine procedure we examined the $75^{\circ}$ and $105^{\circ}$ meridians. In the characteristic early stages the $75^{\circ}$ meridian of the right eye is affected and the $105^{\circ}$ meridian of the left eye, the $105^{\circ}$ (RE) and the $75^{\circ}$ (LE) meridians being normal. In a later stage the $105^{\circ}(\mathrm{RE})$ and the $75^{\circ}$ (LE) meridians also show a defect.

Because of the rapid deterioration of the visual fields the patient was admitted to the Department of Neurology of the Wilhelmina Gasthuis on 31 August 1976. Bilateral carotid angiography, performed on 1 September 1976, gave little or no indication of a pituitary lesion.

Sella tomography was not performed (because of 

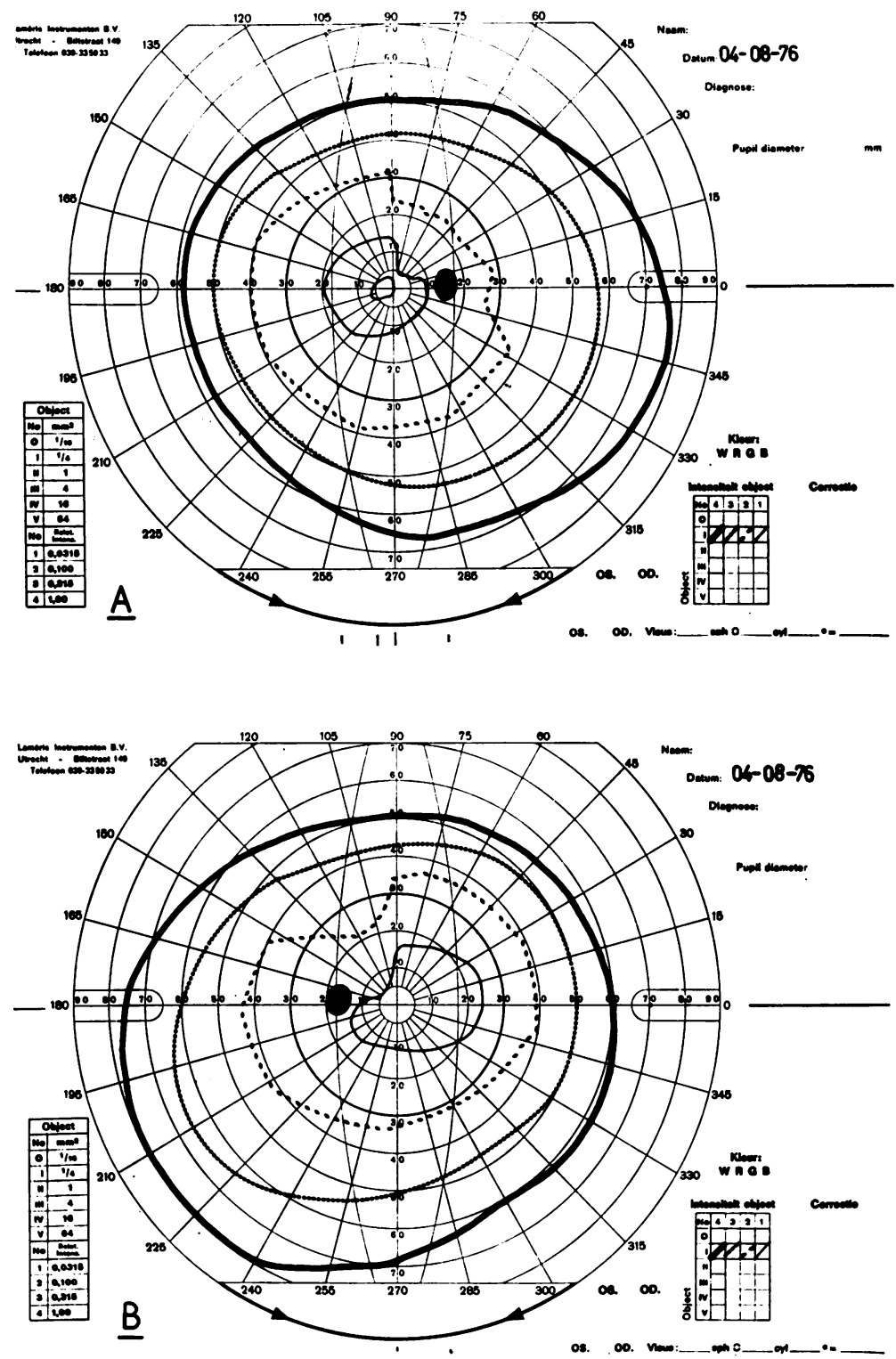

Fig. 1 A, right eye; $\mathrm{B}$, left eye. Early bitemporal defects as shown by the Goldmann perimeter (4 August 1976) the risk of radiation exposure). On 5 September 1976 the patient was transferred to the Neurosurgical Department of the Wilhelmina Gasthuis for surgery, and a small adenoma of the pituitary was found. At the time of operation the pregnancy was 28 weeks and obstetrically normal.

Postoperatively the visual fields returned to normal.

Mother and child are in good health at the time of publication of this report.

\section{Discussion}

It is well known that the pituitary gland increases in volume during pregnancy. This enlargement is moderate, and it seems unlikely that the increase in volume during pregnancy would cause chiasmal compression, although according to several authors a large percentage of pregnant women develop defects in their visual fields, varying from a peripheral contraction to a bitemporal hemianopia, 


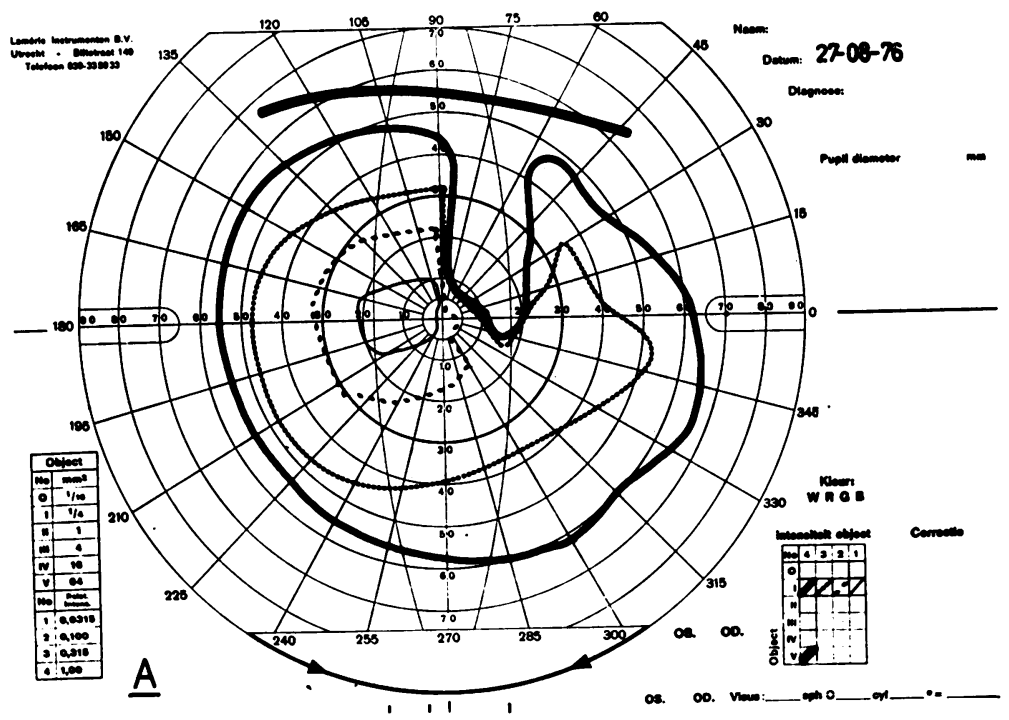

Fig. $2 \mathrm{~A}$, right eye; $\mathrm{B}$, left eye. Deterioration of the bitemporal defects in a period of 23 days

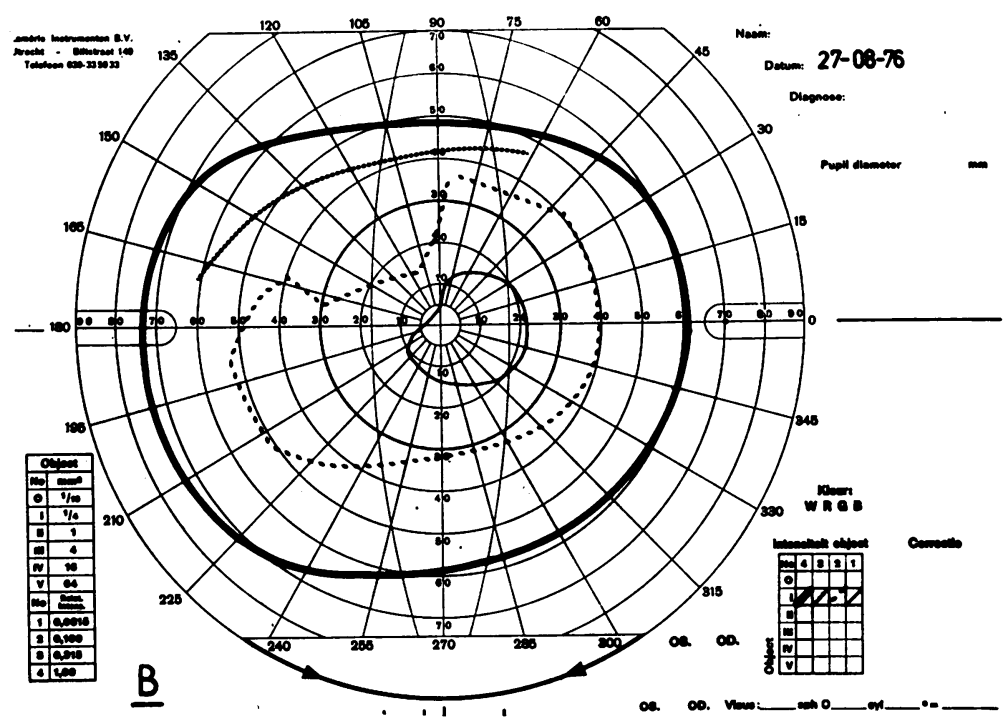
(27 August 1976)

which usually disappears after delivery (Carill, 1923; Finley, 1934).

Of special interest is the production or activation of pituitary adenoma during pregnancy (as was the case with our patient). Duke-Elder (1949) states: 'The evidence is strong that in certain cases during pregnancy adenomatous changes may be stimulated or accelerated in the pituitary, that these may eventually involve complete bitemporal hemianopia and may progress in subsequent pregnancies so that eventual operative removal of the neoplasm is necessary'. Definite rules for treatment are difficult to give. Enoksson et al. (1961) state that if chiasmal compression is detected during early pregnancy the tumour should be treated according to ordinary neurosurgical principles, that is, removed as soon as possible.

If compression is revealed during the last 3 months of pregnancy, expectant treatment under continued surveillance of the visual fields is preferable. Rapid, 

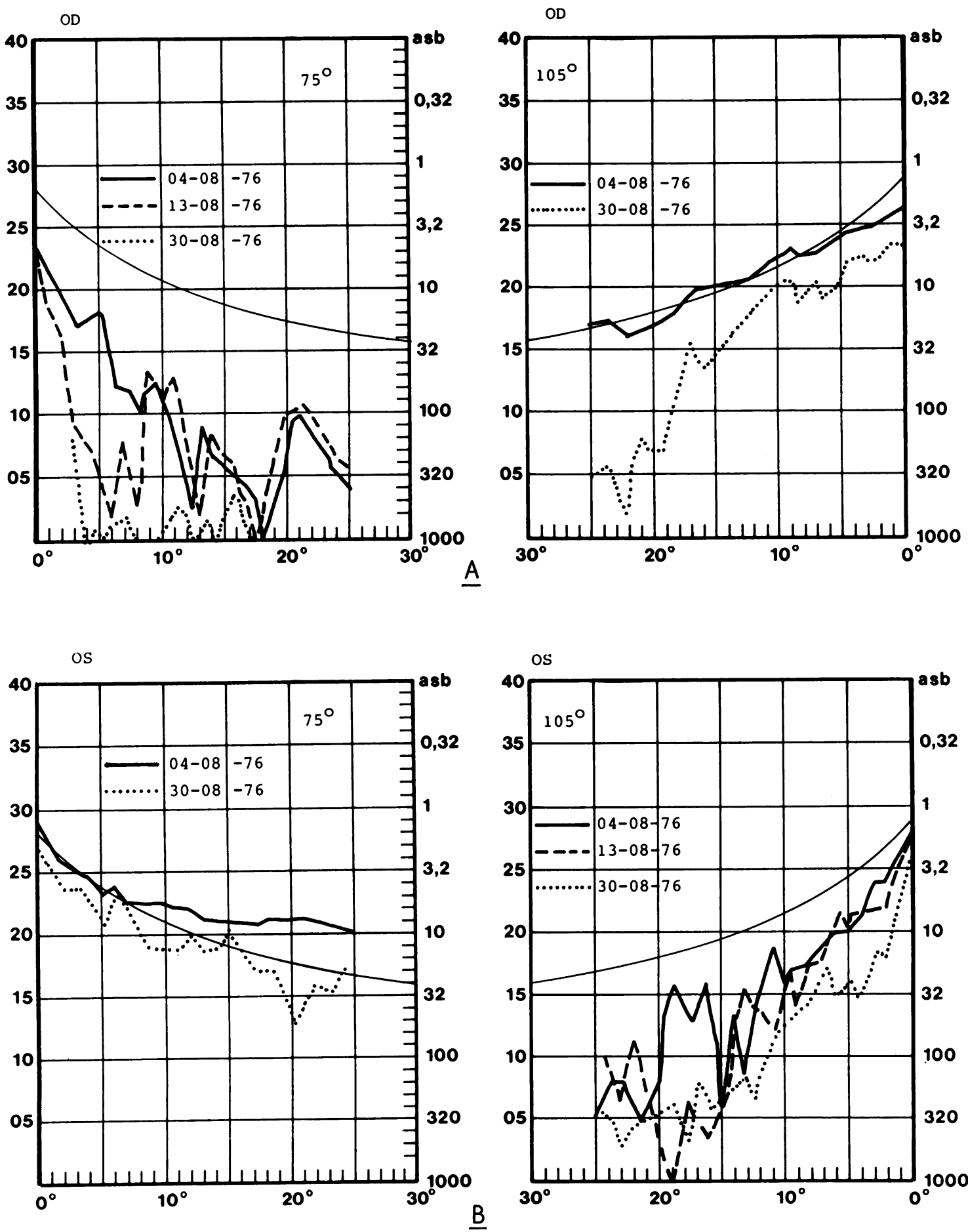

Fig. 3 A, right eye; B, left eye. Follow-up of the bitemporal defects by means of static perimetry 
severe deterioration of vision may then indicate either immediate craniotomy or, if the child is viable, induction of labour.

Hagedoorn's criteria for hypophysectomy were the following (Hagedoorn, 1937): 'In cases with bitemporal hemianopia, if vision in the better eyes diminishes to one-third to one-half, pregnancy should be terminated. If abortion is refused one may wait till vision in the better eye is $1 / 40$. If a living child is not possible at that time treatment by the neurosurgeon is indicated.' Falconer and StaffordBell (1975) stated that the treatment of choice whenever vision is seriously threatened at any stage of pregnancy is a surgical attack on the pituitary, followed by suitable replacement therapy to ensure that the pregnancy continues.

In our case the visual fields showed very rapid deterioration, passing in approximately $\mathbf{3 0}$ days from almost normal to a large bitemporal defect in one eye and a moderate defect in the other eye, threatening the visual acuity of both eyes, and strongly suggesting the presence of an active pituitary adenoma (at that time the pregnancy was 28 weeks).

There were no really convincing radiographic changes in the sellar region, so that the patient was subjected to operation on the grounds of the increase in the visual field defect as detected by means of the careful and repeated perimetry, including static perimetry. Moreover, our patient was rather a rarity in that she had evidence of a pituitary (micro) adenoma and a pregnancy 'induced' with bromocriptine.

The visual fields returned to normal after decompression, showing that the operation was performed in time. The reversibility of bitemporal defects in the visual fields after surgical decompression of the chiasma depends on the extent and intensity of the compression. Long-standing absolute defects usually show little postoperative regression.
The performance of hypophysectomy in this patient averted the need for a (premature) termination of the pregnancy.

\section{Conclusions}

A pregnant woman suspected of a pituitary lesion should have frequent and careful perimetric examinations. This report of bitemporal defects in the visual fields in a bromocriptine-induced pregnancy following an amenorrhoea-galactorrhoea syndrome seems to indicate that surgical decompression of the chiasma can be considered in such cases.

We thank Miss M. A. Raakman for the skilful perimetry.

\section{References}

Carill, M. (1923). Bitemporal contraction of the fields of vision in pregnancy. American Journal of Ophthalmology, 6, 885-891.

Corbey, R. S., Cruysberg, J. R. M., and Rolland, R. (In press). Visual field abnormalities in a pregnancy induced by bromocriptine medication.

Enoksson, P., Kindberg, N., and Sjösteds, S. B. (1961). Influence of pregnancy on visual fields in suprasellar tumors. Acta Psychiatrica Scandinavica, 36, 524-538.

Duke-Elder, W. S. (1949). Textbook of Ophthalmology, Vol. 4, p. 3508. H. Kimpton: London.

Falconer, M. A. and Stafford-Bell, M. A. (1975). Visual failure from pituitary and parasellar tumours occurring with favourable outcome in pregnant women. Journal of Neurology, Neurosurgery, and Psychiatry, 38, 919-930.

Finley, C. E. (1934). Visual field defects in pregnancy. Archives of Ophthalmology, 13, 207-219.

Hagedoorn, A. (1937). The chiasmal syndrome and retrobulbar neuritis in pregnancy. American Journal of Ophthalmology, 20, 690-699.

Lamberts, S. W. J., et al. (In press). Transient bitemporal hemianopia during pregnancy after treatment of galactorrhoea-amenorrhoea syndrome with bromocriptine.

Kajtar, T., and Tomkin, G. H. (1971). Emergency hypophysectomy in pregnancy after induction of ovulation. British Medical Journal, 4, 88-90. 